\title{
The Role of Ephrins-B1 and -B2 During Fetal Rat Lung Development
}

\author{
Francisca O Peixoto ${ }^{a, b}$ Patrícia Pereira-Terra ${ }^{a, b} \quad$ Rute S Moura ${ }^{a, b, c}$ \\ Emanuel Carvalho-Dias ${ }^{a, b, d} \quad J o r g e$ Correia-Pinto ${ }^{a, b, d} \quad$ Cristina Nogueira-Silva, ${ }^{a, b, e}$ \\ aLife and Health Sciences Research Institute (ICVS), School of Health Sciences, University of Minho, \\ Braga, Portugal; 'DICVS/3B's - PT Government Associate Laboratory, Braga/Guimarães, 'Biology \\ Department, School of Sciences, University of Minho, Braga, ${ }^{4}$ Department of Urology, Hospital de \\ Braga, Braga, 'Department of Pediatric Surgery, Hospital de Braga, Braga, ${ }^{e}$ Department of Obstetrics \\ and Gynecology, Hospital de Braga, Braga, Portugal
}

\author{
Key Words \\ Ephrin-B1 • Ephrin-B2 • EphB4 • Fetal lung development • Branching
}

\begin{abstract}
Background/Aims: The knowledge of the molecular network that governs fetal lung branching is an essential step towards the discovery of novel therapeutic targets against pulmonary pathologies. Lung consists of two highly branched systems: airways and vasculature. Ephrins and its receptors, Eph, have been implicated in cardiovascular development, angiogenesis and vascular remodeling. This study aims to clarify the role of these factors during lung morphogenesis. Methods: Ephrins-B1, -B2 and receptor EphB4 expression pattern was assessed in fetal rat lungs between 15.5 and 21.5 days post-conception, by immunohistochemistry. Fetal rat lungs were harvested at $13.5 \mathrm{dpc}$, cultured during 4 days and treated with increasing doses of ephrins-B1 and -B2 and the activity of key signaling pathways was assessed. Results: Ephrin-B1 presents mesenchymal expression, whereas ephrin-B2 and its receptor EphB4 were expressed by the epithelium. Both ephrins stimulated pulmonary branching. Moreover, while ephrin-B1 did not affect the pathways studied, ephrin-B2 supplementation decreased activity of JNK, ERK and STAT. This study characterizes the expression pattern of ephrins-B1, -B2 and EphB4 receptor throughout rat lung development. Conclusion: Our data highlight a possible role of ephrins as molecular stimulators of lung morphogenesis. Moreover, it supports the idea that classical vascular factors might play a role as airway growth promoters.
\end{abstract}

F.O. Peixoto and P. Pereira-Terra contributed equally to this manuscript.

Cristina Nogueira-Silva, MD, PhD

KARGER 125
Life and Health Sciences Research Institute (ICVS), School of Health Sciences, University of Minho, Campus de Gualtar; 4710-057 Braga (Portugal)

Tel. +351 253604 909; E-Mail cristinasilva@ecsaude.uminho.pt 


\section{Introduction}

Lung morphogenesis is a very complex and tightly regulated phenomenon. Transcription factors, extracellular matrix molecules, intercellular adhesion molecules and soluble growth factors have been identified as controlling factors of pulmonary development. Together, these molecular players act along the proximal-distal axis of the respiratory tract and influence local expression of specific genes that ultimately play a preponderant role on the development of the immature lung [1].

The Eph receptors and their ligands, ephrins, constitute the largest subgroup of the family of receptors tyrosine kinase (RTKs). This family of receptors is divided into two subgroups based on the similarity of their extracellular domain sequences, whereas ephrins are classified according to their structure and their affinity for the correspondent receptor subgroup [2]. Regarding ephrins-B, Eph/ephrin signaling can be bi-directional, inducing intracellular pathways downstream of both the Eph receptor and the ephrin ligand. The latter is definied as reverse signaling [3]. Albeit ephrins-A preferably bind to EphA and ephrins-B to EphB receptors, ephrins are also able to bind and activate Eph receptors from the opposite subgroup [4]. Nevertheless, some ephrins seem to have higher affinity for specific receptors as reported for ephrin-B2, which mainly binds to EphB4 receptor [5, 6].

The roles of ephrins in cell adhesion, vascular development, cell migration and tissueborder maintenance highlight a potential role in lung branching morphogenesis $[3,7]$. In fact, ephrins expression has been described in other organs that, as the lung, develop through branching processes. For instance, the expression of ephrins-B1 and -B2, and EphB4 (ephrin-B2 cognate receptor) has been confirmed in adult mouse mammary gland and fetal mouse pancreas [8-10]. The expression of ephrin-B2 and its receptor has also been detected in fetal mouse kidney [11]. It is noteworthy that ephrin-B1 mutations have been found in nearly $87 \%$ of craniofrontonasal syndrome cases. Some of these cases exhibit diaphragmatic defects and consequently lung defects [12-16]. Moreover, another study described ephrin-B1 gene (EFNB1) duplications in fetuses that died from $\mathrm{CDH}$ and concomitant pulmonary hypoplasia and pulmonary hypertension [17]. On the other hand, ephrin-B2 and EphB4 receptor have been widely described as arterial and venous markers, respectively, and implicated in the development of the vascular system during embryogenesis $[5,6,18,19]$. Ephrin-B2, ephrin-B1 and EphB4 receptor RNA was identified in sorted endothelial cells from mouse adult lung [20].

There is extensive evidence for a direct synergism between pulmonary vascular and airway development. Indeed, vascular regulatory factors play a crucial role in airway and alveolar morphogenic processes, and growth factors produced in the airway epithelium can also regulate vasculature formation [21-24].

Ephrins have been described as crucial for microvascular maturation mainly during septum maturation and capillary remodeling from double into a single capillary layer. They are also known to be involved in the process of alveologenesis, contributing for the establishment of the secondary septa and for alveolar formation [25, 26]. In fact, ephrin-B2 has been described as a contributor to normal postnatal alveolar development as its inhibition leads to arrested alveolar and abrogated lung vascular growth. Moreover, in a setting where ephrin-B2 is downregulated, ephrin-B2 treatment preserves alveolar and lung vascular growth attenuating pulmonary hypertension caused by $\mathrm{O}_{2}$-induced arrested alveolar growth $[27,28]$. Ephrin-B1 -B2 and EphB4 knockout mice die during embryogenesis and displayed several defects including angiogenesis impairment. In published data with Ephrin-B2 or EphB4 knockout mice, stained vessels were completely absent in knockouts [28, 29]. Thus, ephrin-B1, ephrin-B2 and its main receptor appear as potential key players in fetal lung development. Nonetheless, very little is known regarding ephrins-B1 and -B2 function during fetal lung development. Hence, in the present work we aimed to disclose novel roles of such proteins in normal lung development. 


\section{Materials and Methods}

\section{Ethics Statement}

Animal experiments were performed according to the Portuguese law for animal welfare ('Diário da República, Portaria 1005/92') and the protocol was approved by the Committee on the Ethics of Animal Experiments of the Life and Health Sciences Research Institute of the University of Minho (DGV 022162 - 520/000/000/2006). Animals were housed in an accredited house and treated as specified by the recommendations of the 'Guide for the Care and Use of Laboratory Animals' published by the US National Institutes of Health (NIH Publication No.85-23, revised 1996). Moreover, all efforts were made to minimize animal suffering.

\section{Experimental Design and Animal Model}

Sprague-Dawley female rats (225g, Charles-River) were maintained in appropriate cages under controlled conditions and fed with commercial solid food. The rats were mated and checked daily for vaginal plug. The day of plugging was defined as gestational day 0.5 for time dating purposes.

Fetuses were removed by caesarean section at 13.5, 15.5, 17.5, 19.5 and 21.5 days post-conception $(\mathrm{dpc})$. Fetuses were sacrificed by decapitation, its lungs dissected under a binocular surgical microscope (Leica MZFLIII, Leica Microsystems $\mathrm{GmbH}$ ) and processed either for immunohistochemistry (IHC) or western blot studies. $13.5 \mathrm{dpc}$ fetal lungs were also collected to perform explant culture.

\section{Immunohistochemistry}

IHC was performed on paraformaldehyde-fixed and paraffin-embedded lungs. Sections (4 $\mu \mathrm{m})$ were then placed on SuperFrost ${ }^{\circledR}$ Plus slides (Menzel-Glaser, J1800AMNZ). After $15^{\prime}$ at $65^{\circ} \mathrm{C}$, slides were dewaxed in xylene and rehydrated in ethanol. Antigen retrieval was achieved by boiling the slides in $1 \mathrm{mM}$ citrate buffer (Thermo Scientific, AP-9003-125) followed by cooling down at room temperature. Incubation with $3 \%$ hydrogen peroxide (Sigma, 95313-500 ml) in distilled water for 20' allowed quenching endogenous peroxidase. Incubation with primary antibodies occurred at $4^{\circ} \mathrm{C}$ overnight. The primary antibodies used were a polyclonal goat anti-ephrin-B1 in a $25 \mu \mathrm{g} / \mathrm{mL}$ concentration (R\&D Systems, Inc., AF473), a polyclonal rabbit anti-ephrin-B2 (Santa Cruz Biotechnology Inc., sc-15397) in a 1:25 dilution and a polyclonal rabbit anti-EphB4 in a 1:100 dilution (Santa Cruz Biotechnology, Inc., sc-5536). Negative control reactions included omission of the primary antibody. The incubation with the corresponding secondary antibodies occurred at room temperature and was carried according to manufacturer's instructions. Ephrin-B1: goat ImmunoCruz ${ }^{\mathrm{TM}}$ Staining System (Santa Cruz Biotechnology Inc., sc-2023). Ephrin-B2 and EphB4: UltraVision detection system anti-polyvalent horseradish peroxidase (Thermo Scientific, TP-125-H2). To visualize peroxidase activity, 3,3'-diaminobenzidine tetrahydrochloride (Dako, K3468) was used. Sections were counterstained with $50 \%$ hematoxylin.

\section{Fetal lung explant cultures}

After harvesting and dissection, $13.5 \mathrm{dpc}$ lungs were transferred to $8 \mu \mathrm{m}$ Isopore membranes (Millipore, TETP01300) previously soaked in DMEM (Lonza, 12-604F) for 1 hour. Cultures were then incubated in $200 \mu \mathrm{L}$ of complex medium, 50\% Dulbecco's modified eagle medium (DMEM), 50\% nutrient mixture F-12 (Invitrogen, Carlsbad, CA, USA) supplemented with $100 \mathrm{mg} / \mathrm{mL}$ streptomycin, 100 units/mL penicillin (Invitrogen), $0.25 \mathrm{mg} / \mathrm{mL}$ ascorbic acid (Sigma-Aldrich, St Louis, MO, USA) and 10\% fetal bovune serum (Invitrogen) [30]. After 1 hour of incubation, recombinant ephrin-B1 (R\&D Systems Inc., 473-EB200) and ephrin-B2 (R\&D Systems Inc., 496-EB-200) were added to lung explants in order to achieve a final concentration of $0.01,0.1$ and $1 \mu \mathrm{g} / \mathrm{mL}$. The recombinant ephrins were daily added. The four experimental groups (control and three doses for each protein) were all constituted by $n=12$ lungs. The explants were incubated in a $5 \% \mathrm{CO}_{2}$ incubator, at $37^{\circ} \mathrm{C}$, during 96 hours. The medium was replaced at 48 hours. The explants were daily photographed to monitor branching morphogenesis. At day $0\left(D_{0}: 0\right.$ hours) and day $4\left(D_{4}\right.$ : 96 hours) of culture, the total number of peripheral airway buds (branching), the epithelial perimeter, the external area and external perimeter were determined for all lung explants using the Image 1.44 software (National Institutes of Health, USA). The results of branching, epithelial perimeter and area were expressed as $\mathrm{D}_{4} / \mathrm{D}_{0}$ ratio. At the end of the incubation time, explants were washed in PBS and stored at $-80^{\circ} \mathrm{C}$ until use. 
Peixoto et al.: Ephrins-B1 and -B2 in Fetal Lung Development

\section{Western blot}

Three different pooled samples of fetal lungs for each gestational age (13.5 - $21.5 \mathrm{dpc}$ ) (obtained from different pregnant female rats), and cultured lungs (treated with ephrin-B1 at $1 \mu \mathrm{g} / \mathrm{mL}$, ephrin-B2 at $0.01 \mu \mathrm{g} / \mathrm{mL}$ and non-treated) were processed for western blot analysis. Proteins were obtained according to Kling et al. [31]. Twenty-five or five micrograms (for explants) of protein were loaded in 12\% acrylamide mini gel, electrophoresed and then transferred to nitrocellulose membranes (HybondTM -C Extra, GE Healthcare Life Sciences, 25800047). Blots were probed with polyclonal goat anti-ephrin-B1 (1:750; R\&D Systems, Inc., AF473), polyclonal rabbit anti-ephrin-B2 (1:2000; Santa Cruz Biotechnology Inc., sc-15397), polyclonal rabbit anti-EphB4 (1:200, Abcam, ab123791), and with antibodies to non-phosphorylated and phosphorylated forms of p38 (8690, 4511), p44/42 (ERK1/2) (4695, 4370), JNK (9258, 4671), Akt (4685, 13038) and STAT3 $(12640,9131)$ (1:1000; Cell Signaling Technology Inc.) according to manufacturer's instructions. Activity of intracellular signaling pathways from lung explants was measured by the ratio between phosphorylated protein and total protein amount. The data was also normalized against the control group. For loading control, blots were probed with $\beta$-tubulin (1:200000; Abcam, ab6046).

Blots were incubated with a secondary anti-rabbit horseradish peroxidase conjugate (Santa Cruz Biotechnology Inc., sc-2004), developed with Super Signal West Femto Substrate (Pierce Biotechnology Inc., 34095) and the chemiluminescent signal was captured using the Chemidoc XRS (Bio-Rad). Quantitative analysis was performed with Quantity One 4.6.5 1-D Analysis Software (Bio-Rad Laboratories Ltd).

\section{Statistical Analysis}

Data are presented as mean \pm SEM. Statistical analysis was performed using the statistical software GraphPad Prism (version 5; GraphPad Software Inc., USA). Statistical comparison of experimental groups was achieved by t-test and one-way ANOVA on ranks. The Student-Newman-Keuls test was used for posttest analysis. Statistical significance was set at $\mathrm{p}<0.05$.

\section{Results}

Pulmonary expression pattern of ephrin-B1, ephrin-B2 and EphB4 receptor

In order to determine ephrin-B1, ephrin-B2 and its receptor EphB4 expression pattern during fetal lung development, immunohistochemical analysis was performed for five different gestational ages: 13.5, 15.5, 17.5, 19.5 and $21.5 \mathrm{dpc}$. Ephrin-B1 exhibits strong mesenchymal expression observed in all gestational ages (Fig. 1A). Faint epithelial expression is detected at 15.5 and $17.5 \mathrm{dpc}$. Nonetheless, from $19.5 \mathrm{dpc}$ on, the epithelial expression is absent, as well as endothelial expression.

Remarkably, ephrin-B2 expression pattern is highly distinct from ephrin-B1 (Fig. 1B). Ephrin-B2 is predominantly expressed in the epithelial compartment, and it is also observed in the cells surrounding the epithelium at 13.5 and $15.5 \mathrm{dpc}$. Additionally, ephrin-B2 is not detected in vascular smooth muscle cells neither in endothelial cells. At $21.5 \mathrm{dpc}$, ephrin-B2 expression appears to be restricted only to epithelial cells from terminal and respiratory bronchioles.

EphB4 expression pattern (Fig. 1C) is very similar to its cognate ligand: mainly detected in epithelial structures throughout all gestational ages. Interestingly, at 13.5 and $15.5 \mathrm{dpc}$, EphB4 receptor is also weakly expressed in potentially less differentiated cells surrounding the epithelium. This expression seems to diminish as the fetal lung maturates, becoming progressively specific to the epithelium. On the other hand, again no expression was detected in vascular structures, namely smooth muscle or endothelial cells from both arterial and venous structures.

Ephrins-B1 and -B2, and EphB4 receptor protein expression levels were assessed by western blot analysis (Fig. 2). For the gestational ages studied, EphB4 receptor, ephrins-B1 and -B2 expression was detected at relatively constant levels. Nevertheless, despite the higher variation in ephrin-B1 expression levels throughout all gestational ages, no statistical significant differences were found. 


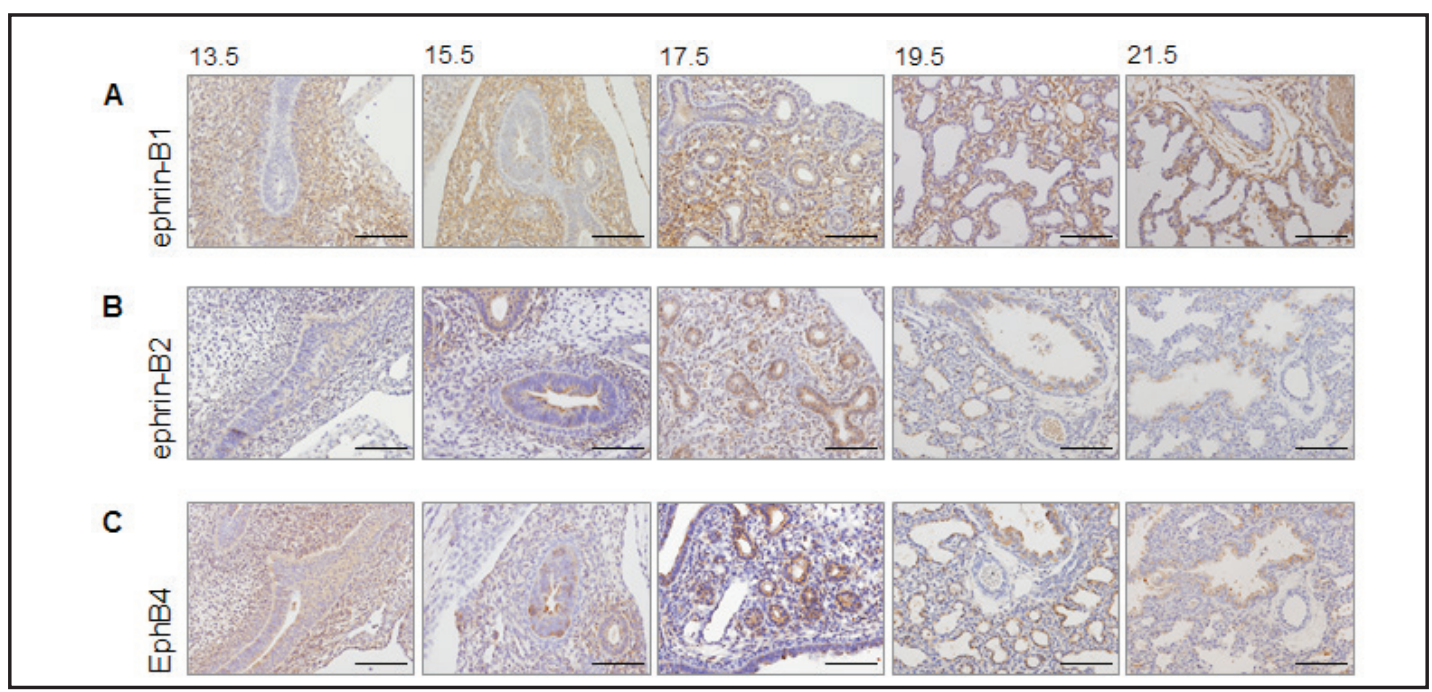

Fig. 1. Ephrin-B1 (A), ephrin-B2 (B) and EphB4 receptor (C) protein expression pattern, during fetal lung development. Five different gestational ages were analyzed: 13.5, 15.5, 17.5, 19.5 and 21.5 days post-conception (dpc). Ephrin-B2 and receptor EphB4 display a strong epithelial expression, while ephrin-B1 expression is mainly detected in mesenchymal cells. Original magnification: $\mathrm{x} 200$. Scale bar $=100 \mu \mathrm{m}$ (all images at same magnification). No staining was observed in the negative controls for each protein. (data not shown).

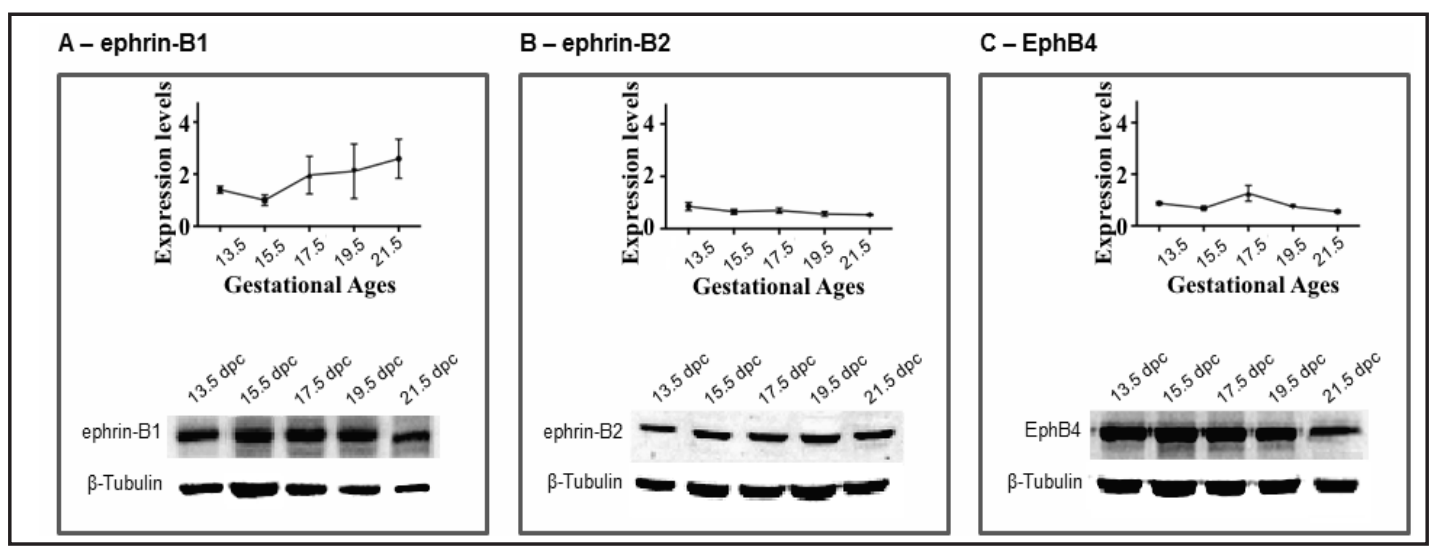

Fig. 2. Western Blot analysis of the expression levels of ephrin-B1 (A), ephrin-B2 (B) and EphB4 receptor (C) during fetal lung development. Five different gestational ages were analyzed: 13.5, 15.5, 17.5, 19.5 and 21.5 days post conception ( $\mathrm{dpc}$ ). Loading control was performed using $\beta$-tubulin. Relative protein levels were expressed in arbitrary units normalized for $\beta$-tubulin. Statistical analysis showed no significant differences between gestational stages.

\section{Ephrin-B1 and ephrin-B2 affect fetal lung morphogenesis in rat}

Aiming to unveil ephrins-B1 and -B2 potential role in fetal lung development, functional studies were performed using lung explant cultures. Explants were daily supplemented with three different doses of either ephrin-B1 or ephrin-B2 recombinant protein (selected according to literature). Morphometric analysis revealed a statistically significant effect of both ligands on lung morphogenesis. Recombinant ephrin-B1 promoted an increase in the number of peripheral airway buds regardless of the dose tested (Fig. 3B). On its turn, ephrin-B2 lowest dose $(0.01 \mu \mathrm{g} / \mathrm{mL})$ significantly increased lung branching and the internal epithelial perimeter (Fig. $4 \mathrm{~B}$ and C, respectively). Moreover, ephrin-B2 treated explants present an increase in total lung area regardless of the dose studied (Fig. 4D).

\section{KARGER}


A

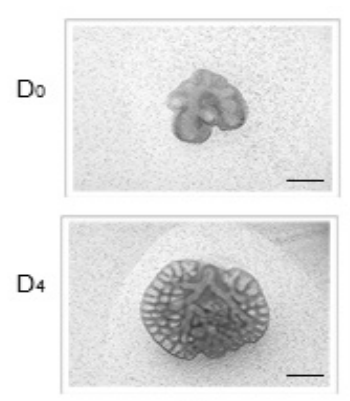

C

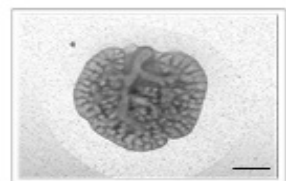

$0.01 \mu \mathrm{g} / \mathrm{mL}$

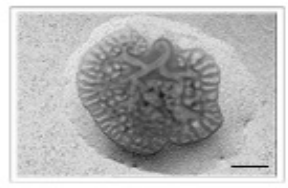

$0.1 \mu \mathrm{g} / \mathrm{mL}$

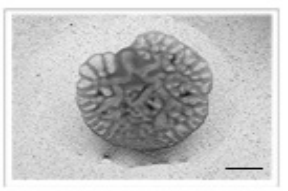

$1 \mu \mathrm{g} / \mathrm{mL}$
B

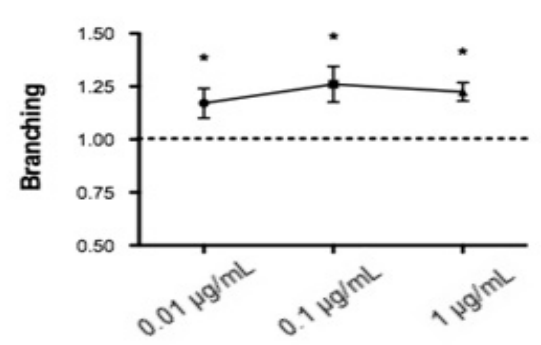

D

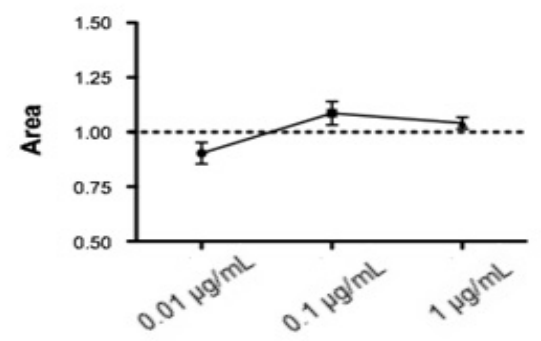

c

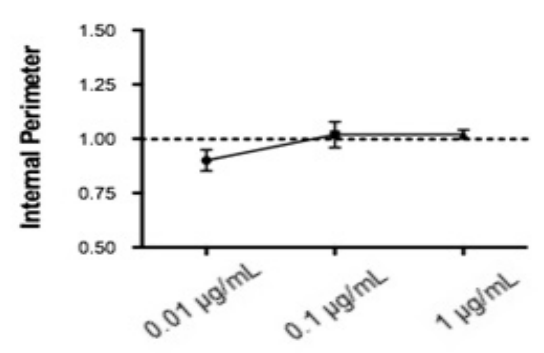

E

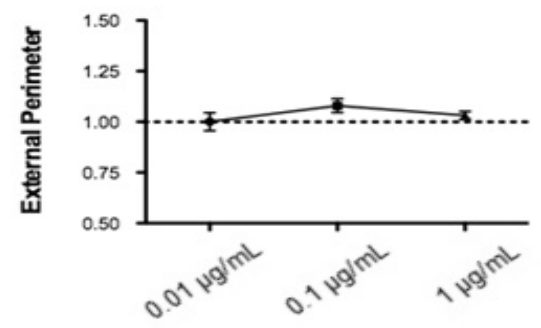

Fig. 3. Ephrin-B1 supplementation promotes branching of rat fetal lung explants. (A) Representative examples of fetal lung explants cultured with three different doses of ephrin-B1 recombinant protein $(0.01,0.1$ and $1 \mu \mathrm{g} / \mathrm{mL})$ at day zero $\left(\mathrm{D}_{0}\right)$ and day $4\left(\mathrm{D}_{4}\right)$. Original magnification x25. Morphometric analysis of branching (B), internal perimeter (C), area (D), and external perimeter (E). A significant increase in the number of peripheral airway buds (branching) was observed for all tested doses. All data was normalized with the control group ( $\mathrm{C}=1$; dashed lines). Original magnification $\mathrm{x} 25$. Scale bar $=6349 \mu \mathrm{m}$ (all images at same magnification). Results are expressed as D4/D0 ratio. $\mathrm{p}<0.05$ : $^{*}$ vs. control group.

\section{Ephrin-B2 influences the phosphorylated form of ERK, JNK and STAT3}

The signaling pathways that act downstream ephrin-B1 and ephrin-B2, specifically in lung morphogenesis, are poorly understood. In order to further investigate the effect of ephrins on fetal rat lung growth, treated lung explants were assessed for intracellular signaling pathways known to regulate lung growth and development.

Pooled samples of lung explants treated with $0.01 \mu \mathrm{g} / \mathrm{mL}$ of recombinant ephrin-B1 or $1 \mu \mathrm{g} / \mathrm{mL}$ of recombinant ephrin-B2 (selected according to its maximal effect on lung explants growth) were evaluated for modulation of p38, p44/42 (ERK1/2), JNK, Akt and STAT3 pathways (Fig. 5). Ephrin-B1 treatment did not influence the phosphorylation levels of the analyzed pathways. Strikingly, recombinant ephrin-B2 administration promoted the inactivation of ERK, JNK and STAT signaling pathways in fetal lung explants. 


\section{A}

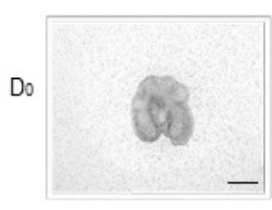

D4

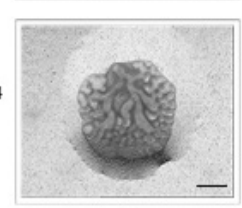

C

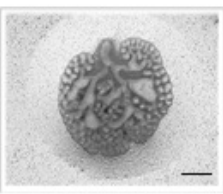

$0.01 \mu \mathrm{g} / \mathrm{mL}$

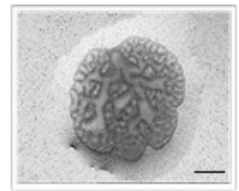

$0.1 \mu \mathrm{g} / \mathrm{mL}$

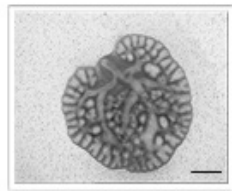

$1 \mu \mathrm{g} / \mathrm{mL}$
B

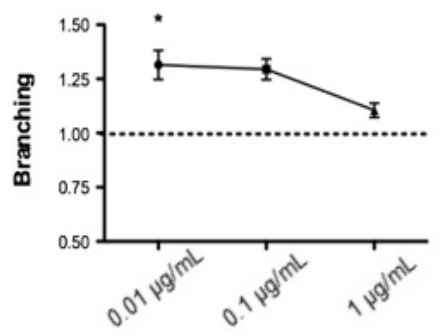

D

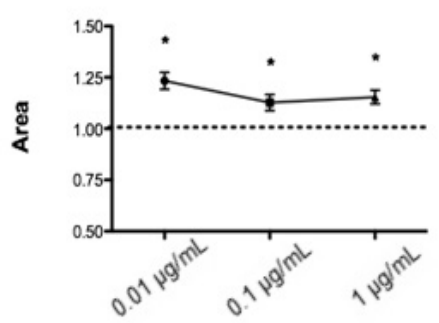

C

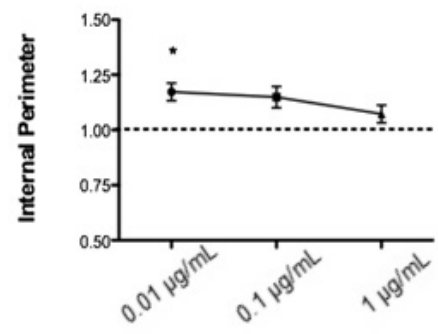

E

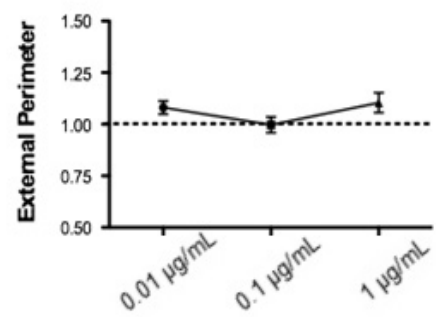

Fig. 4. Ephrin-B2 supplementation induces growth of rat fetal lung explants. (A) Representative examples of fetal lung explants cultured with three different doses of ephrin-B2 recombinant protein $(0.01,0.1$ and $1 \mu \mathrm{g} / \mathrm{mL})$ at day zero $\left(\mathrm{D}_{0}\right)$ and day $4\left(\mathrm{D}_{4}\right)$. Original magnification $\mathrm{x} 25$. Scale bar $=6349 \mu \mathrm{m}$ (all images at same magnification). Morphometric analysis of branching (B), internal perimeter (C), area (D), and external perimeter (E). A significant increase in the area of the explants was observed for all tested doses. The lowest dose significantly stimulated both branching and internal perimeter. All data was normalized with the control group ( $\mathrm{C}=1$; dashed lines). Results are expressed as $\mathrm{D} 4 / \mathrm{D} 0$ ratio. $\mathrm{p}<0.05:{ }^{*}$ vs. control group.

\section{Discussion}

There is growing evidence for the involvement of ephrins in numerous biological processes. Clearly, this family of proteins is implicated in regulation of key steps of embryonic development. This study demonstrates that two ephrin ligands - B1 and B2 - and one wellestablished ephrin-B2 receptor - EphB4 - are constitutively expressed during fetal lung development. Two recent studies presented strong evidence for the role of ephrin-B2 in lung morphogenesis and repair [27, 32]. Our findings not only provide further proof of ephrin-B2 function but also show how yet another ephrin ligand promotes branching of the rat fetal lung.

The constitutive and stable protein expression levels of ephrins-B1 and -B2, and EphB4 receptor particularly during early gestational stages, which are characterized by 


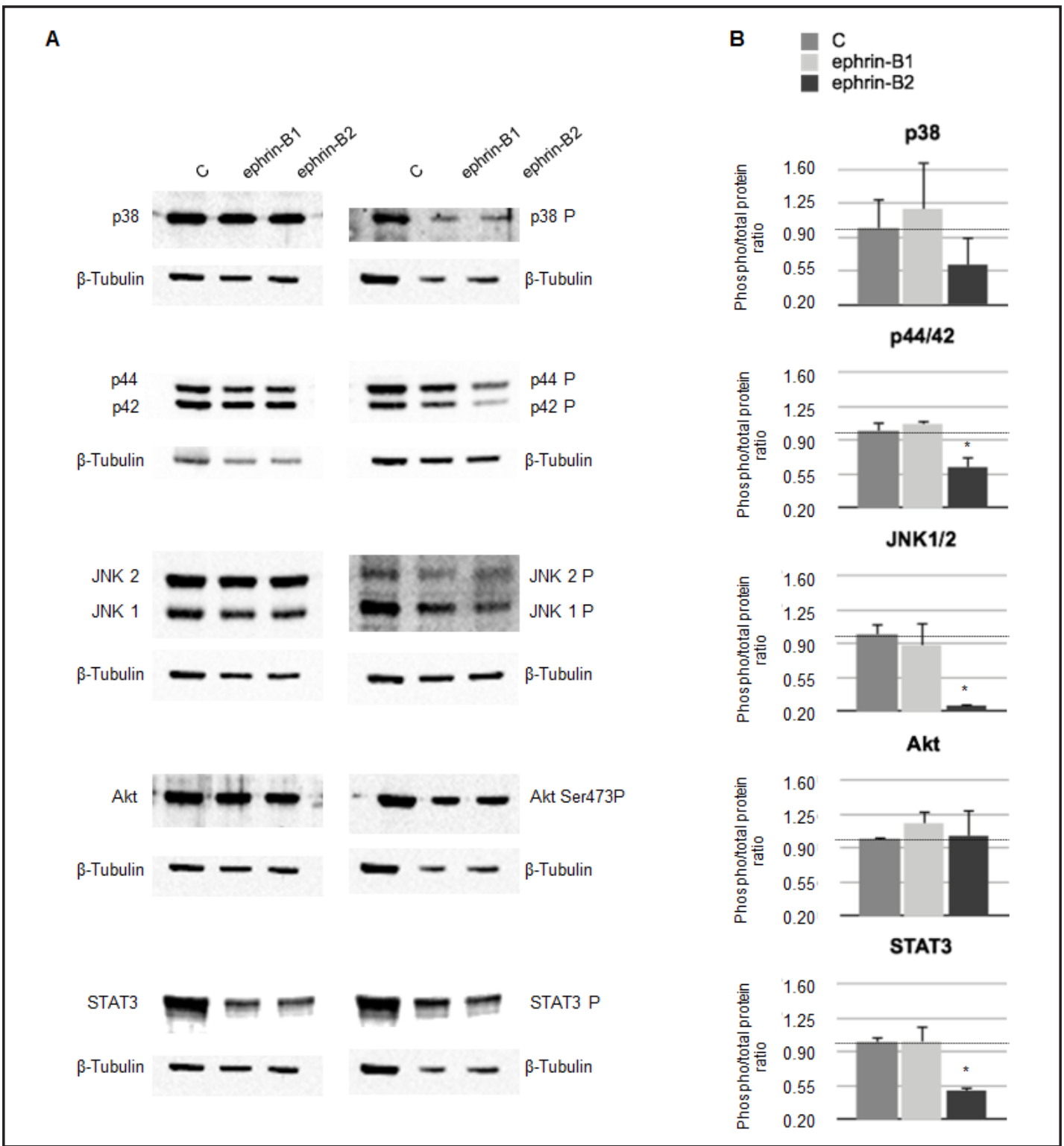

Fig. 5. Analysis of the intracellular signaling pathways that mediate Ephrin-B1 and Ephrin-B2 actions in lung morphogenesis. (A) Western blot analysis of p38, p44/42, JNK1/2, Akt and STAT3, and phosphorylated forms of p38 (p38 P), p44/42 (p44/42 P), JNK (JNK P), Akt serine 473 (Akt Ser473P) and STAT3 (STAT3 P) in control, ephrin-B1 (at $0.01 \mu \mathrm{g} / \mathrm{mL}$ ) and ephrin-B2 (at $1 \mu \mathrm{g} / \mathrm{mL}$ ) treated lung explants. Loading control was performed using $\beta$-tubulin. p38 corresponds to $38 \mathrm{kDa}$. p44 and 42 correspond to 44 and $42 \mathrm{kDa}$, respectively. JNK1 and 2 correspond to 46 and $54 \mathrm{kDa}$, respectively. Akt corresponds to $60 \mathrm{kDa}$. STAT3 corresponds to two bands, 79 and $86 \mathrm{kDa}$. (B) Semi-quantitative analysis of phosphorylated forms of these intracellular signaling pathways that mediate lung growth. No changes in activity levels of these pathways were observed for ephrin-B1 treated lung explants. Ephrin-B2 caused a significant decrease in p44/42, JNK1/2 and STAT3 signaling activity. Results are presented as arbitrary units normalized for $\beta$-tubulin. Activity of intracellular signaling pathways was measured by the ratio between phosphorylated protein and total protein amount. All data was also normalized against the control group ( $C=1$; dashed lines). $\mathrm{p}<0.05$ : * vs. control group.

intense ramification and growth phenomena, underscore them as potential players in fetal lung branching. On the other hand, the distinct expression patterns presented by the two ligands suggest distinct or, perhaps, synergistic functions. Ephrin-B1 expression was 
mainly detected in mesenchymal tissue, whereas strong epithelial expression was found for ephrin-B2 and the receptor EphB4. Interactions between epithelial structures and the surrounding mesenchyme are known to dictate and to be essential for proper branching of the lung epithelium [33-35]. Therefore, our results suggest a so far undervalued contribution from this RTK subfamily of ligands to such mesenchymal-epithelial interactions that guide lung branching morphogenesis.

Although ephrin-B2 and its receptor have been widely described as angiogenic factors $[5,6,18,19]$, epithelial expression of ephrin-B2 has been described in fetal mouse kidney and mammary gland $[9,11]$, also branching organs. Both ephrin-B1 and ephrin-B2 are also expressed by the pancreas epithelium [10]. In $17 \mathrm{dpc}$ mice lung, ephrin-B2 expression has been observed in the epithelium. However, at $18 \mathrm{dpc}$ ephrin-B2 was also expressed in some endothelial cells and, more weakly, in non-endothelial cells with epithelial morphology [36]. In human fetal lung, ephrin-B2 is expressed in the pulmonary arterial endothelium and EphB4 expressed in endothelial cells of the pulmonary vein, primary capillary plexus and pulmonary artery [37]. In rat lung, endothelial staining was absent for the three proteins studied. These results are in agreement with observations from a recent knock-in mouse model in which the intracellular domain of ephrin-B2 was replaced by bacterial $\beta$-gal sequences. The same study showed how ephrin-B2 reverse signaling blockage results in pulmonary hypoplasia and decreased lung compliance [32]. Finally, in the adult mice lung, both ephrins are enriched in the endothelial compartment [20]. The different observations in fetal lung might be due to the chosen study model and technical approach. Nevertheless, all together these observations suggest an intense endothelial-epithelial crosstalk played by these proteins since early stages of the fetal development to the adult organism. Indeed, vascular regulatory factors are crucial for airway and alveolar morphogenic processes. In fact, growth factors produced in the airway epithelium are able to regulate vasculature formation $[38,39]$. Taking all this into account, we hypothesized that both ephrins-B1 and -B2 would affect fetal lung growth and branching morphogenesis.

In order to evaluate ephrins-B1 and -B2 role in lung branching morphogenesis, fetal lung explants were cultured with increasing doses of ephrin-B1 or ephrin-B2. Ephrin-B1 supplementation stimulated the formation of peripheral airway buds. Additionally, ephrin-B2 supplementation increased not only lung branching but also the internal epithelial perimeter and area of the lung explants. These results strongly support a stimulatory role of ephrin-B1 and ephrin-B2 during fetal lung development. The importance of ephrins-B1 and -B2 in different tissues during embryogenesis is highlighted by the lethality of ephrin-B1 knockout mice [29] and angiogenesis impairment caused by ephrin-B2 gene disruption [5]. Also, in a recent study, ephrin-B2 was shown, by means of siRNA mediated gene silencing, to be implicated in normal postnatal alveolar development. Authors observed decreased alveolarization associated with fewer pulmonary vessels [27].

Aiming to identify the signaling pathways that mediate the effect of ephrins-B1 and -B2 in lung growth, the activity of p38, ERK, JNK, Akt and STAT3 proteins was studied. Many factors that regulate fetal lung branching morphogenesis activate signaling pathways that culminate with MAPK, PI3K/Akt and p38 cascades [30, 31, 40-42]. In the present study, ephrin-B1 was found not to modify the phosphorylated levels of these proteins. In a different study it has been already described that ephrin-B1 signaling does not activate the p38 and ERK signaling pathways. However, ephrin-B1 led to the phosphorylation of JNK on a specific residue. Therefore, the putative phosphorylation of JNK in different residues from the ones here studied cannot be rule out [43]. A very recent study has shown that CNK1 (Connector Enhancer of KSR1) is required for the ephrin-B1-dependent JNK phosphorylation [44]. It would be interesting in future studies to access the role of this protein in the context of ephrin-B1 mediated fetal lung branching. Moreover, it would also be interesting to check if Shh, Retinoic Acid, Bmp or Fgf signaling pathways, classical regulators of lung branching, are changed when ephrin-B1 is administrated [45-49].

In contrast, ephrin-B2 stimulation induced a decrease in phosphorylated levels of ERK, JNK and STAT3, indicating a decrease in these intracellular signaling. These results 
might reflect regulatory loops in which ephrin-B2, by stimulating other branchingpromoter pathways, leads to lower activity of the specific pathways here studied. Regarding ERK, although classically this pathway has been implicated as a promoter of branching morphogenesis, it was already described that ERK pathway can be involved in lung growth inhibition $[42,50]$. In a lung explant culture system similar to the one used in the present study, stimulation with leukemia inhibitory factor and concomitant activation of ERK pathway resulted in branching inhibition [50]. Recent published data has also shown that knockdown of ephrin-B2 results in increased phosphorylation levels of several kinases such as ERK, STAT, c-Jun. This indicates that multiple prominent cell signaling pathways are affected by changes of EphB2 activity [51]. The putative involvement of ERK, JNK and STAT3 in lung growth inhibition might still be an indirect or balancing effect of the activation of other pathways or simply context dependent. Further investigation will help to determine whether the inactivation of such pathways is essential for ephrin-B2 function in lung development or if the obtained results reflect crosstalk and modulation by other non-canonical intracellular pathways.

In summary, this study demonstrated that both ephrin-B2 and its cognate receptor EphB4 are constitutively expressed in pulmonary epithelium, whereas ephrin-B1 is mainly expressed in the mesenchyme of the rat fetal lung. It is now clear that both ephrin-B1 and ephrin-B2 significantly influence lung morphogenesis. However, further investigation will be necessary to properly describe the expression pattern and functional contribution of other members of the ephrin-B subfamily of ligands as they might act synergistically. Ultimately, in vivo studies will be crucial to further confirm these factors as promoters of lung branching morphogenesis.

\section{Acknowledgments}

We would like to thank Luís Martins and Miguel Carneiro for histological technical support and help on animal euthanasia. This project was funded by Fundação para a Ciência e a Tecnologia (PTDC/SAU-OBD/108051/2008). PPT was supported by POPH/ FSE by Fundação para a Ciência e a Tecnologia (reference SFRH/BD/73660/2010) and FOP was supported by Fundação para a Ciência e a Tecnologia (reference UMINHO/BII/172/2009).

\section{References}

\footnotetext{
1 Copland I, Post M: Lung development and fetal lung growth. Paediatr Respir Rev 2004;5: S259-264.

2 Eph Nomenclature Committee: Unified nomenclature for Eph family receptors and their ligands, the ephrins. Cell 1997;90:403-404.

3 Klein R: Eph/ephrin signalling during development. Development 2012;139:4105-4109.

-4 Himanen JP, Chumley MJ, Lackmann M, Li C, Barton WA, Jeffrey PD, Vearing C, Geleick D, Feldheim DA, Boyd AW, Henkemeyer M, Nikolov DB: Repelling class discrimination: ephrin-A5 binds to and activates EphB2 receptor signaling. Nat Neurosci 2004;7:501-509.

-5 Wang HU, Chen ZF, Anderson DJ: Molecular distinction and angiogenic interaction between embryonic arteries and veins revealed by ephrin-B2 and its receptor Eph-B4. Cell 1998;93:741-753.

-6 Adams RH, Wilkinson GA, Weiss C, Diella F, Gale NW, Deutsch U, Risau W, Klein R: Roles of ephrinB ligands and EphB receptors in cardiovascular development: demarcation of arterial/venous domains, vascular morphogenesis, and sprouting angiogenesis. Genes Dev 1999;13:295-306.

7 Kullander K, Klein R: Mechanisms and functions of Eph and ephrin signalling. Nat Rev Mol Cell Biol 2002;3:475-486.

-8 Kouros-Mehr H, Werb Z: Candidate regulators of mammary branching morphogenesis identified by genome-wide transcript analysis. Dev Dyn 2006;235:3404-3412.
} 
Peixoto et al.: Ephrins-B1 and -B2 in Fetal Lung Development

9 Nikolova Z, Djonov V, Zuercher G, Andres AC, Ziemiecki A: Cell-type specific and estrogen dependent expression of the receptor tyrosine kinase EphB4 and its ligand ephrin-B2 during mammary gland morphogenesis. J Cell Sci 1998;111:2741-2751.

10 van Eyll JM, Passante L, Pierreux CE, Lemaigre FP, Vanderhaeghen P, Rousseau GG: Eph receptors and their ephrin ligands are expressed in developing mouse pancreas. Gene Expr Patterns 2006;6:353-359.

11 Takahashi T, Takahashi K, Gerety S, Wang H, Anderson DJ, Daniel TO: Temporally compartmentalized expression of ephrin-B2 during renal glomerular development. J Am Soc Nephrol 2001;12:2673-2682.

12 Hogue J, Shankar S, Perry H, Patel R, Vargervik K, Slavotinek A: A novel EFNB1 mutation (c.712delG) in a family with craniofrontonasal syndrome and diaphragmatic hernia. Am J Med Genet A 2010;152A:25742577.

13 Vasudevan PC, Twigg SR, Mulliken JB, Cook JA, Quarrell OW, Wilkie AO: Expanding the phenotype of craniofrontonasal syndrome: two unrelated boys with EFNB1 mutations and congenital diaphragmatic hernia. Eur J Hum Genet 2006;14:884-887.

- 14 Twigg SR, Matsumoto K, Kidd AM, Goriely A, Taylor IB, Fisher RB, Hoogeboom AJ, Mathijssen IM, Lourenco MT, Morton JE, Sweeney E, Wilson LC, Brunner HG, Mulliken JB, Wall SA, Wilkie AO: The origin of EFNB1 mutations in craniofrontonasal syndrome: frequent somatic mosaicism and explanation of the paucity of carrier males. Am J Hum Genet 2006;78:999-1010.

15 Wallis D, Lacbawan F, Jain M, Der Kaloustian VM, Steiner CE, Moeschler JB, Losken HW, Kaitila II, Cantrell S, Proud VK, Carey JC, Day DW, Lev D, Teebi AS, Robinson LK, Hoyme HE, Al-Torki N, Siegel-Bartelt J, Mulliken JB, Robin NH, Saavedra D, Zackai EH, Muenke M: Additional EFNB1 mutations in craniofrontonasal syndrome. Am J Med Genet A 2008;146A:2008-2012.

16 Wieland I, Jakubiczka S, Muschke P, Cohen M, Thiele H, Gerlach KL, Adams RH, Wieacker P: Mutations of the ephrin-B1 gene cause craniofrontonasal syndrome. Am J Hum Genet 2004;74:1209-1215.

17 Srisupundit K, Brady PD, Devriendt K, Fryns JP, Cruz-Martinez R, Gratacos E, Deprest JA Vermeesch JR: Targeted array comparative genomic hybridisation (array CGH) identifies genomic imbalances associated with isolated congenital diaphragmatic hernia (CDH). Prenat Diagn 2010; 30: 1198-1206.

18 Shin D, Garcia-Cardena G, Hayashi S, Gerety S, Asahara T, Stavrakis G, Isner J, Folkman J, Gimbrone MA Jr, Anderson DJ: Expression of ephrinB2 identifies a stable genetic difference between arterial and venous vascular smooth muscle as well as endothelial cells, and marks subsets of microvessels at sites of adult neovascularization. Dev Biol 2001;230:139-150.

19 Gale NW, Baluk P, Pan L, Kwan M, Holash J, DeChiara TM, McDonald DM, Yancopoulos GD: Ephrin-B2 selectively marks arterial vessels and neovascularization sites in the adult, with expression in both endothelial and smooth-muscle cells. Dev Biol 2001;230:151-160.

20 Favre CJ, Mancuso M, Maas K, McLean JW, Baluk P, McDonald DM: Expression of genes involved in vascular development and angiogenesis in endothelial cells of adult lung. Am J Physiol Heart Circ Physiol 2003;285:H1917-1938.

-21 Jakkula M, Le Cras TD, Gebb S, Hirth KP, Tuder RM, Voelkel NF, Abman SH: Inhibition of angiogenesis decreases alveolarization in the developing rat lung. Am J Physiol Lung Cell Mol Physiol 2000;279:L600607.

22 DeLisser HM, Helmke BP, Cao G, Egan PM, Taichman D, Fehrenbach M, Zaman A, Cui Z, Mohan GS, Baldwin HS, et al: Loss of PECAM-1 function impairs alveolarization. J Biol Chem 2006;281:8724-8731.

23 Schwarz MA, Zhang F, Gebb S, Starnes V, Warburton D: Endothelial monocyte activating polypeptide II inhibits lung neovascularization and airway epithelial morphogenesis. Mech Dev 2000;95:123-132.

24 Zeng X, Wert SE, Federici R, Peters KG, Whitsett JA: VEGF enhances pulmonary vasculogenesis and disrupts lung morphogenesis in vivo. Dev Dyn 1998;211:215-227.

-25 Wilkinson GA, Schittny JC, Reinhardt DP, Klein R: Role for ephrinB2 in postnatal lung alveolar development and elastic matrix integrity. Dev Dyn 2008;237:2220-2234.

26 Oike Y, Ito Y, Hamada K, Zhang XQ, Miyata K: Regulation of vasculogenesis and angiogenesis by EphB/ ephrin-B2 signaling between endothelial cells and surrounding mesenchymal cells. Blood 2002;100:13261333.

27 Vadivel A, van Haaften T, Alphonse RS, Rey-Parra GJ, Ionescu L, Haromy A, Eaton F, Michelakis E, Thébaud B: Critical role of the axonal guidance cue EphrinB2 in lung growth, angiogenesis, and repair. Am J Respir Crit Care Med 2011;185:564-574. 
Peixoto et al.: Ephrins-B1 and -B2 in Fetal Lung Development

28 Adams RH, Diella F, Hennig S, Helmbacher F, Deutsch U: The cytoplasmic domain of the ligand ephrinB2 is required for vascular morphogenesis but not cranial neural crest migration. Cell 2001;104:57 -69.

29 Davy A, Aubin J, Soriano P: Ephrin-B1 forward and reverse signaling are required during mouse development. Genes Dev 2004;18:572-583.

-30 Nogueira-Silva C, Santos M, Baptista MJ, Moura RS, Correia-Pinto J: IL-6 is constitutively expressed during lung morphogenesis and enhances fetal lung explant branching. Pediatr Res 2006;60:530-536.

-31 Kling DE, Lorenzo HK, Trbovich AM, Kinane TB, Donahoe PK, Schnitzer JJ: MEK-1/2 inhibition reduces branching morphogenesis and causes mesenchymal cell apoptosis in fetal rat lungs. Am J Physiol Lung Cell Mol Physiol 2002;282:L370-378.

-32 Bennett KM, Afanador MD, Lal CV, Xu H, Persad E, Legan SK, Chenaux G, Dellinger M, Savani RC, Dravis C, Henkemeyer M, Schwarz MA: Ephrin-B2 Reverse Signaling Increases alpha5beta1 Integrin Mediated Fibronectin Deposition and Reduces Distal Lung Compliance. Am J Respir Cell Mol Biol 2013;49: 680-687.

-33 Masters JR: Epithelial-mesenchymal interaction during lung development: the effect of mesenchymal mass. Dev Biol 1976;51:98-108.

34 Bluemink JG, Van Maurik P, Lawson KA: Intimate cell contacts at the epithelial/mesenchymal interface in embryonic mouse lung. J Ultrastruct Res 1976;55:257-270.

- 35 Hogan BL, Yingling JM: Epithelial/mesenchymal interactions and branching morphogenesis of the lung. Curr Opin Genet Dev 1998;8:481-486.

-36 Wilkinson GA, Schittny JC, Reinhardt DP, Klein R: Role for ephrinB2 in postnatal lung alveolar development and elastic matrix integrity. Dev Dyn 2008;237:2220-2234.

- 37 Hall SM, Hislop AA, Haworth SG: Origin, differentiation, and maturation of human pulmonary veins. Am J Respir Cell Mol Biol 2002;26:333-340.

-38 Schwarz MA, Caldwell L, Cafasso D, Zheng H: Emerging pulmonary vasculature lacks fate specification. Am J Physiol Lung Cell Mol Physiol 2009;296:L71-81.

39 Morrisey EE, Hogan BL: Preparing for the first breath: genetic and cellular mechanisms in lung development. Dev Cell 2010;18:8-23.

40 Piairo P, Moura RS, Nogueira-Silva C, Correia-Pinto J: The apelinergic system in the developing lung: expression and signaling. Peptides 2011;32:2474-2483.

-41 Nogueira-Silva C, Carvalho-Dias E, Piairo P, Nunes S, Baptista MJ, Moura RS, Correia-Pinto J: Local fetal lung renin-angiotensin system as a target to treat congenital diaphragmatic hernia. Mol Med 2012;18:231-243.

-42 Nogueira-Silva C, Piairo P, Carvalho-Dias E, Veiga C, Moura RS, Correia-Pinto J: The role of glycoprotein 130 family of cytokines in fetal rat lung development. PLoS One 2013;8:e67607.

43 Huynh-Do U, Vindis C, Liu H, Cerretti DP, McGrew JT: Ephrin-B1 transduces signals to activate integrinmediated migration, attachment and angiogenesis. J Cell Sci 2002;115:3073-3081.

-44 Cho HJ, Hwang YS, Mood K, Ji YJ, Lim J: EphrinB1 interacts with CNK1 and promotes cell migration through c-Jun N-terminal kinase (JNK) activation. J Biol Chem 2014;289:18556-18568.

45 Baptista MJ, Melo-Rocha G, Pedrosa C, Gonzaga S, Teles A. Antenatal vitamin A administration attenuates lung hypoplasia by interfering with early instead of late determinants of lung underdevelopment in congenital diaphragmatic hernia. J Pediatr Surg 2005;40: 658-665.

-46 Moura RS, Coutinho-Borges JP, Pacheco AP, Damota PO, Correia-Pinto J. FGF signaling pathway in the developing chick lung: expression and inhibition studies. PLoS One 2011;6:e17660.

-47 Metzger RJ, Klein OD, Martin GR, Krasnow MA: The branching programme of mouse lung deve- lopment. Nature 2008;453:745-751.

-48 Morrisey EE, Hogan BL: Preparing for the first breath: genetic and cellular mechanisms in lung development. Dev Cell 2010;18:8-23.

-49 Correia-Pinto J, Gonzaga S, Huang Y, Rottier R: Congenital lung lesions-underlying molecular mechanisms. Semin Pediatr Surg 2010;19:171-9.

-50 Nogueira-Silva C, Piairo P, Carvalho-Dias E, Peixoto FO, Moura RS, Correia-Pinto J: Leukemia inhibitory factor in rat fetal lung development: expression and functional studies. PLoS One 2012;7:e30517.

-51 Sikkema AH1, den Dunnen WF, Hulleman E, van Vuurden DG, Garcia-Manero G, Yang H, Scherpen FJ, Kampen KR, Hoving EW, Kamps WA, Diks SH, Peppelenbosch MP, de Bont ES: EphB2 activity plays a pivotal role in pediatric medulloblastoma cell adhesion and invasion. Neuro-Oncology 2012;14:1125-1135. 